\title{
A INSTITUCIONALIZAÇÃO DO SISTEMA NACIONAL DE EDUCAÇÃO E O PLANO NACIONAL DE EDUCAÇÃO: PROPOSIÇÕES E DISPUTAS
}

\author{
Luiz Fernandes Dourado ${ }^{1}$
}

\begin{abstract}
RESUMO: Este artigo busca contextualizar e problematizar o Sistema Nacional de Educação a partir de artigos sobre a temática publicados na última década em Educação \& Sociedade, bem como as proposiçóes sintonizadas a sua aprovação no marco da Constituição Federal, por meio da Emenda Constitucional no 59/2009, e da institucionalização do Sistema Nacional de Educação pela materialização (ou não) do Plano Nacional de Educaçáo (Lei no 13.005/2014). Para isso, examinarse-ão as iniciativas do Fórum Nacional de Educação, resultado das deliberaçóes de conferências nacionais (CONEB, 2008, CONAE, 2010 e 2014), do Ministério da Educação e da Câmara dos Deputados, situando as tensóes e concepçóes em disputa.
\end{abstract}

Palavras-chave: Sistema Nacional de Educação. Plano Nacional de Educação. Fórum Nacional de Educação. Fórum Nacional Popular de Educação. Conferência Nacional de Educação. Conferência Nacional Popular de Educação. Federalismo. Educação \& Sociedade.

\section{INSTITUTIONALIZATION OF THE NATIONAL EDUCATION SYSTEM AND THE NATIONAL EDUCATION PLAN: PROPOSITIONS AND DISPUTES}

\begin{abstract}
This article seeks to contextualize and problematize the National Education System from articles on the theme published over the last decade in Education \& Society. It also looks at those proposals in harmony with its approval with in the framework of the Federal Constitution, as a result of the Constitutional Amendment n. 59/2009, together with the institutionalization of the National Education System as a result of the concretization (or not) of the National Education Plan (Law n. 13.005/2014). To this end, the initiatives of the National Education Forum, stemming from the deliberations of national conferences (CONEB, 2008, CONAE, 2010 and 2014), the Ministry
\end{abstract}

\footnotetext{
${ }^{1}$ Universidade Federal de Goiás, Programa de Pós-graduação em Educação - Goiânia (GO), Brasil. E-mail: luizdourado1@gmail.com DOI: 10.1590/ES0101-73302018203079
} 
of Education and the Chamber of Deputies, will be examined and the conceptions under dispute will be identified.

Keywords: National Education System. National Education Plan. National Education Forum. National Popular Education Forum. National Education Conference. National Popular Education Conference. Federalism. Education \& Society.

\section{L'INSTITUTIONNALISATION DU SYSTÈME NATIONAL D'ÉDUCATION ET LE Plan NATIONAL D'ÉdUCATION: PROPOSITIONS ET LITIGES}

RÉSUMÉ: Cet article cherche à contextualiser et à problématiser le Système National d'Éducation à partir d'articles sur le theme publiés dans la dernière décennie dans Educação \& Sociedade (Éducation et Société), ainsi que les propositions approuvées dans le cadre de la Constitution Fédérale, à travers l'Ammendement Constitutionnel n. 59/2009, et de l'institutionnalisation du Système National d'Éducation par la matérialisation (ou pas) du Plan National d'Éducation (Loi n. 13.005/2014). À cette fin, les initiatives du Forum National de l'Éducation, à la suíte des délibérations des conférences nationales (CONEB, 2008, CONAE, 2010 e 2014), du Ministère de l'Éducation et de la Chambre des Députés, seront examinées, permettant de situer les tensions et les conceptions en litige.

Mots-clés: Système National d'Éducation. Plan National d'Éducation. Forum National de l'Éducation. Forum Populaire d'Éducation Nationale. Conférence Nationale de l'Éducation. Conférence Nationale Populaire sur l'Éducation. Fédéralisme. Educação \& Sociedade (Éducation et Société).

\section{Introdução}

A trajetória das políticas e da gestão da educação no Brasil, incluindo seus processos de regulação e avaliação, é permeada por disputas de projetos e concepçôes distintas sobre o papel do Estado e, consequentemente, sobre o planejamento (ou sua ausência), a relação entre os entes federados e suas obrigações constitucionais. A história da educação no Brasil também é marcada pela interpenetração entre as esferas pública e privada, em detrimento do público.

Vivenciamos um processo de descentralização no campo educativo, atribuído à Constituição Federal (CF), mas que se expressa marcadamente pela desconcentração, sob a qual a atribuição de responsabilidades nem sempre se faz 
acompanhar por condiçóes técnicas, político-pedagógicas e de financiamento. Isso tem gestado formas de organização com forte protagonismo e centralização da União que, por definição constitucional, coordena as políticas nacionais, em detrimento da efetiva participação e autonomia dos demais entes federados.

O processo, ao longo da história, sofreu pequenas alteraçóes em busca de mais articulação e participação entre os entes federados, mas, paradoxalmente, foi marcado por retrocessos dentro de uma lógica política hegemônica na qual a descontinuidade é um simulacro da continuidade.

Disputas e concepçôes diversas vão se deslindando, historicamente, afetando as políticas, que acabam circunscritas à perspectiva governamental, não assumindo escopo mais abrangente como política de Estado - decorrente de ampla participação envolvendo a sociedade civil e política - e, desse modo, geram mudanças e dinâmicas (des)contínuas na organização, na gestão e no financiamento dos sistemas, suas redes e instituiçóes de educação básica e superior.

Esse cenário requer esforços no sentido de se avançar em prol de um federalismo cooperativo - envolvendo, entre outros, efetivo regime de colaboração entre os entes federados - que se consubstancie, estruturalmente, pela articulação entre planos educacionais decenais e a instituição de um sistema nacional de educação. Esse artigo se propóe a situar os antecedentes históricos, as questōes e os embates que permeiam o Sistema Nacional de Educação (SNE), abordando, no cenário atual, os movimentos em prol da sua institucionalização.

\section{Sistema Nacional de Educação: retomada histórica}

Há várias décadas, a defesa da criação e/ou institucionalização do SNE faz-se presente na agenda educacional brasileira. Trata-se de temática complexa cuja discussáo e trâmite são marcados por proposiçôes, avanços e recuos e, certamente, articulam-se aos complexos processos de consolidação da República, do federalismo e do Estado Democrático de Direito no Brasil.

Um marco dessa discussão sobre sistema está presente no Manifesto dos Pioneiros da Educação Nova (BRASIL, 2010), de 1932, cuja proposição central era a defesa de uma organização sistêmica para a educação nacional que superasse as reformas parciais, o clientelismo e o dualismo das redes em curso no país e que contribuísse para maior organicidade das políticas, com a finalidade de garantir o direito à educação.

Segundo Cury (2008, p. 1191),

[o] Manifesto buscou combater essa dualidade de redes por meio de uma estrutura educacional sob a égide da escola pública. Com currículos e normas comuns, tendo o Estado como 
articulador e legislador, o sistema só se diversificaria após uma escolaridade fundamental comum e para todos. E essa diversificaçáo deveria permitir a todos os seus concluintes o prosseguimento de estudos, mormente no ensino superior.

O debate sobre a educação pública, sua democratização e organização floresce nos anos 1930 e sofre revés com o Estado Novo, que, na contramão dos ideários democráticos, engendra novos contornos às políticas e à gestão, secundarizando os movimentos pela democratização e articulação das políticas educacionais. Com a redemocratização do Estado brasileiro e a proclamação da Constituição de 1946, os debates são retomados e novas inflexóes político-pedagógicas são aprovadas, com destaque para a Lei no 4.024/61, que institui as Leis de Diretrizes e Bases da Educação Nacional (LDB), inserindo o país, "lentamente e por etapas, na sistemática de planejamento setorial e global" (HORTA, 1997, p. 158).

Em 1964, o país vive novo revés com a eclosão do golpe militar em 1964. A ditadura militar é instituída na contramão das reformas de base, incluindo a educacional. O planejamento de Estado, sob o viés tecnocrático (MENDES, 2000, p. 38-39; HORTA, 1997), engendra, por meio de planos setoriais, reformas e alteraçóes legais ao contrário da instituição do SNE. Esta instituição é secundarizada, e a centralização, por parte da Uniâo, é novamente reforçada como lógica estratégica e os planos "são considerados em termos de suas consequências econômicas" (HORTA, 1997, p. 169).

No fim dos anos 1970, as lutas pela retomada do Estado Democrático de Direito no país e pelo estabelecimento de políticas públicas se intensificam, incluindo aquelas em prol da garantia do direito à educação em todos os níveis e modalidades.

Na década de 1980, floresce e ganha densidade a ação de vários segmentos e movimentos sociais, em todas as áreas, à luz do processo constituinte. A CF de 1988 reforça o papel e a autonomia dos entes federados, incluindo os municípios, com suas prerrogativas políticas, administrativas e financeiras, ratificando o federalismo cooperativo.

Articulado à aprovação da CF de 1988 e em decorrência desta, ocorre uma grande movimentação em defesa de novas diretrizes e bases para a educação nacional. No campo educacional, destaca-se, entre outros atores, o Fórum Nacional em Defesa da Escola Pública (FNDEP), com importante incidência na defesa da educação pública, do SNE e do Plano Nacional de Educação (PNE) como políticas de Estado.

Com o apoio dos movimentos do campo educacional, o deputado Octávio Elísio apresenta a proposta de nova LDB. Após tramitação (BRASIL, 1988), marcada por embates diversos envolvendo os defensores do ensino público e priva- 
do e de inúmeros projetos, foi apresentado pelo deputado Jorge Hage e aprovado pela Comissão de Educação e Cultura da Câmara dos Deputados, um substitutivo. Este substitutivo avançava ao propor uma nova estrutura para a educação nacional por meio da criação do SNE, do PNE, do Conselho Nacional de Educação (CNE), como órgáo normativo e de coordenação do SNE, e do Fórum Nacional de Educação (FNE), como instância de consulta e de articulação com a sociedade (ALMEIDA JUNIOR et al., 2014, p. 213). O substitutivo Darcy Ribeiro, com forte apoio governamental, é aprovado e desfigura esse cenário.

Importante ressaltar que, após a aprovação da CF 1988 e na esteira dos organismos multilaterais, reformas foram efetivadas pelo Estado, nos anos 1990, tendo por eixo a desregulamentação e a descentralização das políticas sociais, o que, em muitos casos, efetivou-se como desconcentração. No campo educacional, tal processo assumiu vários desdobramentos, tendo como eixo o processo de municipalização (AZEVEDO, 2002), com forte incidência nas políticas e na gestão da educação básica, especialmente na educação infantil e no ensino fundamental. Tais políticas têm desdobramento nas políticas educacionais, demarcando novos limites ao pacto federativo, sobretudo no que diz respeito à democratizaçâo do acesso e ao financiamento à educação básica.

Esses antecedentes históricos indicam os caminhos e as opçóes hegemônicas adotados no planejamento e nas políticas educacionais de governo, não se efetivando, portanto, como políticas de Estado ampliado, malgrado alguns processos de participação. Na esteira do processo, foi aprovado o PNE 2001-2010 ${ }^{1}$, pela Lei $\mathrm{n}^{\circ} 10.172$, de 9 de janeiro de 2001, que não se constitui em referência-base para o planejamento e as políticas educacionais no país.

Mudanças nas políticas e na gestão da educação efetivam-se nos governos Lula e Dilma, através de propostas de alteraçóes nos marcos legais e novos movimentos de democratização e participação por meio, entre outros, de conferências nacionais de educação (CONEB, 2008; CONAE, 2010 e 2014). Merece destaque a criação, no Governo Lula, do Plano de Desenvolvimento de Educação (PDE), em 2007, que, em detrimento do PNE, passou a ser a referência para as políticas educacionais. Este importante instrumento de coordenação e cooperação se situa em um cenário de recente aprovação do novo Fundo de Manutenção e Desenvolvimento da Educação Básica e de Valorização dos Profissionais da Educação (FUNDEB) e da inscrição constitucional do Piso Salarial Profissional Nacional (PSPN) para os profissionais da educação escolar pública, entre outros avanços decorrentes da Emenda Constitucional (EC) no 53, de 2006.

As conferências nacionais de educação apresentam novas inflexōes político-pedagógicas para o campo, contribuindo, desse modo, para a avaliação das políticas e para a discussão e a defesa de proposiçóes a um novo plano nacional de educação e pela institucionalização do SNE. Trata-se de 
movimento vigoroso na luta em prol de um novo PNE, propiciando condições para a instituiçáo do FNE, a se concretizar no ano de 2010, por meio de Portaria Ministerial.

Nesse cenário, ganha importância e centralidade a alteração do art. 214 da CF 1988, por meio da EC no 59/2009, ao definir a articulação entre o PNE e o SNE, por meio de açóes integradas dos poderes públicos, bem como por definir o estabelecimento de meta de aplicação de recursos públicos em educação em proporção do Produto Interno Bruto (PIB).

A aprovação do PNE, por meio da Lei $n^{\circ} 13.005 / 2014$, a despeito de alguns limites nas questôes atinentes a diversidade, gestâo, avaliação e financiamento (DOURADO, 2017), explicita significativo avanço ao SNE e à cooperação federativa, ao dispor, no art. 13, sobre a institucionalização do SNE e, na estratégia 20.9, acerca da regulamentaçáo do parágrafo único do art. 23 e o art. 211 da CF, no prazo de 2 anos:

Art. 13. O poder público deverá instituir, em lei específica, contados 2 (dois) anos da publicação desta Lei, o Sistema Nacional de Educação, responsável pela articulação entre os sistemas de ensino, em regime de colaboraçáo, para efetivação das diretrizes, metas e estratégias do Plano Nacional de Educação.

20.9) regulamentar o parágrafo único do art. 23 e o art. 211 da Constituiçáo Federal, no prazo de 2 (dois) anos, por lei complementar, de forma a estabelecer as normas de cooperação entre a União, os Estados, o Distrito Federal e os Municípios, em matéria educacional, e a articulação do sistema nacional de educação em regime de colaboração, com equilíbrio na repartição das responsabilidades e dos recursos e efetivo cumprimento das funçôes redistributiva e supletiva da União no combate às desigualdades educacionais regionais, com especial atenção às regiōes Norte e Nordeste (BRASIL, 2014b).

A agenda pela efetiva institucionalização do SNE, contudo, sofre reveses, diante das políticas de ajustes adotadas no país após o golpe parlamentar de 2016, que depôs a presidente eleita (DOURADO, 2017). Por outro lado, é reforçada por análises e proposiçóes em tramitação no Congresso Nacional e é ratificada pela Conferência Nacional Popular de Educação - CONAPE (2018), organizada pelo Fórum Nacional Popular de Educação (FNPE) ${ }^{2}$.

Ante esse complexo processo, faremos a seguir uma incursão teórica sobre o SNE, realçando seus limites e potencialidades, de forma a contribuir com as discussóes posteriores sobre o andamento das proposiçôes na institucionalização desse sistema. 


\section{Concepções, questões, limites e potencialidades do Sistema Nacional de Educação}

Vários atores defendem a necessidade da instituição de um SNE. Essa posição ganhou reforço por meio da aprovação da EC no 59/2009, que trouxe para o corpo constitucional o SNE, e, ainda, pela aprovaçáo do PNE 2014/2024. Além de ser matéria central de debate em importantes espaços, tais como a Conferência Nacional de Educação Básica (BRASIL, 2008) e as Conferências Nacionais de Educação (CONAE) de 2010 e 2014. A materialização do PNE, bem como a institucionalização do SNE, bandeiras do FNPE, foram ratificadas pela CONAPE de 2018 (CONAPE 2018) e pela Carta de Belo Horizonte. Além desse processo, que envolve grande parte dos movimentos sociais ligados à educação, é oportuno destacar que o Ministério da Educação (MEC) e o Congresso Nacional vêm se debruçando sobre a matéria.

Essa agenda instituinte sobre o SNE é permeada por concepçóes em disputa, envolvendo questôes diversas, desde a concepção, objetivos, dinâmica organizativa, coordenação e descentralização — envolvendo ou não instâncias interfederativas, apoio técnico e financeiro, órgãos normativos e fóruns - gestâo, avaliação, valorização dos profissionais da educação, financiamento, entre outras. Um ponto convergente no conjunto das discussóes nos remete à necessidade de maior organicidade das políticas educacionais no país, envolvendo discussōes diversas sobre organização e gestão, financiamento, democratização, qualidade, entre outros.

Visando problematizar essa temática, recuperamos algumas reflexóes e questões que contribuem para sinalizar perspectivas teóricas, face às concepções e disputas no processo de institucionalização do SNE, sinalizando limites, cuidados e potencialidades desse processo.

Num primeiro momento destacamos posiçóes não hegemônicas, contrárias à institucionalização do SNE. A esse respeito, Cury (2008) traz importantes contribuiçóes, que nos auxiliam a compreender os receios para a implantação do SNE, destacando:

[há] um temor de invasão indébita na autonomia dos entes federativos e, com isso, a eventual perda de autonomia destes. Após 164 anos de descentralização, há o medo de uma centralização por parte do Estado federal na qualidade de Estado nacional. Há o receio, por parte do segmento privado na educaçáo escolar, de se ferir a liberdade de ensino e não falta quem assinale o perigo do monopólio estatal. E há também precaução da parte da própria União quanto a uma presença mais efetiva na educação básica, sobretudo no que se refere ao financiamento desta (CURY, 2008, p. 1.200). 
Outra questáo importante refere-se à efetivação do federalismo cooperativo no campo educativo cuja trajetória não tem sido pautada por efetiva cooperaçáo e colaboraçáo entre os entes federados. Ao indicar que a Constituição de 1988 optou por um federalismo cooperativo sob a denominação de regime de colaboração recíproca, descentralizado, com funçóes compartilhadas entre os entes federativos, Cury (2008) faz importantes indagaçôes sobre a necessidade, possibilidades e limites na formalização de um SNE:

Aqui se pode perguntar: se o $₫$ único do artigo 11 da LDB possibilita a integração dos sistemas estaduais e municipais de ensino sob a forma de sistema único de educação básica, por que tal não seria porta aberta para um sistema nacional da educação básica sob as diretrizes e bases da educação nacional? Ademais, não seria lícito inferir que, além da LDB, o Plano Nacional de Educação, o sistema nacional de avaliação, o Conselho Nacional de Educação e o FUNDEB (precedido pelo FUNDEF) não apontam para a necessidade de um sistema nacionalmente articulado?

Em contrapartida, surgem, também, limites e dificuldades para a formalização de um sistema nacional de educação. $\mathrm{O}$ primeiro deles advém da omissão de nossos parlamentares em não terem ainda elaborado a lei complementar, exigida pela Constituição em seu $₫$ único do artigo 23.

O segundo limite insere-se dentro dessa omissão [...].

Tudo isso acaba gerando, na prática, não um federalismo cooperativo e mais um federalismo competitivo, que póe em risco o pacto federativo sob a figura da colaboraçáo recíproca e seus potenciais avanços (CURY, 2008, p. 1202-1203).

Cury (2008), a despeito desse cenário, sinaliza para uma concepção vigorosa de SNE ao afirmar:

[um] sistema de educação supóe, como definição, uma rede de órgãos, instituiçóes escolares e estabelecimentos - fato; um ordenamento jurídico com leis de educação - norma; uma finalidade comum — valor; uma base comum — direito.

Esses quatro elementos devem coexistir como conjunto, como conjunto organizado, como conjunto organizado sob um ordenamento, como conjunto organizado sob um ordenamento com finalidade comum (valor), como conjunto organizado sob um ordenamento com finalidade comum (valor) sob a figura de um direito.

Essa coexistência, pois, supóe unidade e diversidade, essa coexistência supóe unidade e diversidade sem antinomias (ausência de incompatibilidades normativas) [...] (CURY, 2008, p. 1204). 
Essa concepção contribui para uma concepção de sistema nacional que considere a complexidade federativa do país, a autonomia dos entes federados, bem como a organicidade necessária entre os sistemas no campo educativo, seus órgãos normativos e instituiçóes.

Também problematizando o SNE, Saviani (2010a) traz importantes reflexões, destacando-se a concepção de sistema, sua abrangência pública, o papel do $\mathrm{CNE}$, a repartição de responsabilidades, o financiamento do sistema, entre outros.

Ao discutir o SNE e sua construção, o autor afirma:

Trata-se de construir um verdadeiro sistema, isto é, um conjunto unificado que articula todos os aspectos da educação no país inteiro, com normas comuns válidas para todo o território nacional e com procedimentos também comuns, visando a assegurar educaçáo com o mesmo padrão de qualidade a toda a populaçáo do país. [...] não se pode esquecer que o sistema só pode ser público. Portanto, não há que transigir com os direitos de educar dos particulares. As instituiçóes privadas, em suas diferentes modalidades, integrarão o sistema precisamente como particulares. [...] As funçóes normativas e deliberativas do sistema serão exercidas pelo Conselho Nacional de Educaçáo (CNE). Pensado como um órgão revestido das características de autonomia, representatividade e legitimidade, como uma instância permanente e renovada por critérios e periodicidade [...]. Assim sendo, trata-se de um órgão de Estado e não de governo. [...] $\mathrm{Na}$ construção do Sistema Nacional de Educação deve-se ter como referência o regime de colaboração entre a União, os estados, o Distrito Federal e os municípios, conforme disposto na Constituição Federal. Na repartição das responsabilidades, os entes federativos concorrerão na medida de suas peculiaridades e de suas competências específicas consolidadas pela tradição e confirmadas pelo arcabouço jurídico. [...] O financiamento do sistema será compartilhado pelas três instâncias [...]. A responsabilidade principal dos municípios incidirá sobre a construção e conservação dos prédios escolares e de seus equipamentos, assim como sobre a inspeção de suas condições de funcionamento, além, é claro, dos serviços de apoio como merenda escolar, transporte escolar etc. [...] Obviamente, isso não impede que os municípios assumam, em caráter complementar e nos limites de suas possibilidades, responsabilidades específicas no campo educacional, mesmo no âmbito daquelas funçóes que cabem prioritariamente aos estados e à União (SAVIANI, 2010a, p. 776-780).

Essas contribuições abordam os aspectos em disputa, com especial realce para a caracterização pública do sistema, a rediscussão do CNE numa perspectiva de efetivação de sua autonomia, representatividade e legitimidade, a repartição de responsabilidades e o financiamento. São questóes importantes que têm gerado 
muitos debates e que, certamente, contribuem para se repensar o cenário atual de organização e gestão da educação, seus processos de regulação, financiamento e avaliação.

O autor faz um importante alerta sobre o regime de colaboração e o papel da União na coordenação das políticas nacionais:

O Sistema Nacional de Educaçáo integra e articula todos os níveis e modalidades de educaçáo com todos os recursos e serviços que lhes correspondem, organizados e geridos, em regime de colaboração, por todos os entes federativos, sob coordenação da Uniáo. [...] E assumirão responsabilidades diretas nos aspectos que lhes correspondem, por meio das secretarias e conselhos estaduais de Educação e das secretarias e conselhos municipais de Educação, sempre que tal procedimento venha a concorrer para a flexibilização e maior eficácia da operação do Sistema Nacional de Educação, sem prejuízo, evidentemente, do comum padrão de qualidade que caracteriza o Sistema Nacional de Educação (SAVIANI, 2010a, p. 780).

Duarte e Santos (2014) afirmam a existência do SNE como algo projetado e prognosticado para o país ao mesmo tempo em que sinalizam desafios na relação entre os entes federados, com relevantes questóes para o debate:

Esses novos arranjos institucionais contribuíram para reduzir relaçóes intergovernamentais competitivas predatórias entre os níveis de governo? Há efetivamente restriçóes postas à autonomia decisória e de alocação de gasto aos governos subnacionais? Como avaliar o impacto da regulação federal nas prioridades locais de gasto vis a vis os interesses dos grupos sociais com maior capacidade de organização e vocalização? Concluir um estudo com questóes já formuladas pela literatura da área tem por objetivo revelar a importância de aprofundar estudos comparados a respeito das políticas locais de administração dos sistemas educacionais. (DUARTE; SANTOS, 2014, p. 1131).

Tais questionamentos sinalizam desafios para a institucionalização do SNE ao tempo em que propiciam reflexôes necessárias entre a proposição e a materialização de políticas, seus limites e potencialidades.

Outro ponto de grande controvérsia no campo diz respeito à necessidade ou não de regulamentação do regime de colaboração como substrato para a efetiva institucionalização do SNE. Araújo (2010, p. 764), ao situar limites nas concepções sobre a regulamentação do regime de colaboração, inclusive das conferências, destaca o desafio das relaçóes intergovernamentais na distribuição de poder, autoridade e recursos entre os entes federados, independência e interpenetração dos governos. 
Essa análise se articula à concepção de descentralização na ação coordenada e cooperativa entre os entres federados (DOURADO, 2013) e nos remete aos complexos desafios da regulamentação do regime de colaboração, que, ao extrapolar o campo educacional, vincula-se a um projeto de desenvolvimento nacional cujo eixo estruturante é o federalismo cooperativo.

Outra questão diz respeito à relação entre a cooperação federativa e a colaboração entre os sistemas de ensino, suas instâncias normativas, como delineadas hoje e como deverá ser compatibilizada no SNE. A esse respeito, Abicalil (2013), em análise produzida no processo de tramitação do PNE, alerta-nos para os desafios na construção do SNE, com destaque para essas questôes, bem como as do financiamento e da diversidade.

Alguns contornos do SNE a ser criado em lei, até dois anos depois da sanção do PNE, estão delineados e merecerão atenção para compatibilizar suas atribuiçôes com organismos já existentes, instâncias normativas de controle e acompanhamento já implementadas, formas de colaboração já regulamentadas e outras em debate legislativo concomitante [...].

A seleção de atençôes que é indicada aqui guarda direta relação com os temas atinentes aos contornos apontados para o Sistema Nacional de Educação, a cooperação federativa e a colaboração entre sistemas de ensino [...].

Além de tratar competências comuns, aponta para a consideração das condicionalidades para o exercício das autonomias e da complementaridade em cada âmbito federativo interdependente. [...]

Se entendido assim, o passo para a construção de um sistema nacional deve considerar, no caso brasileiro, além de quem faz o quê: sob quais condiçôes faz; com que mediaçóes de complementaridade e assistência; com que reciprocidade normativa; com que transitoriedades; sob qual regramento; e por deliberação de que órgão, instância ou ente? (ABICALIL, 2013, p. 823).

Esses apontamentos teóricos contribuem para a discussão sobre as proposições sobre o SNE em debate no campo. Qual concepção e característica deve nortear o SNE? Como ele se organiza, quais seus princípios, finalidades e objetivos? Que instâncias e tipologias de coordenação configuram sua composição? Que órgãos normativos e de participação serão previstos? Como se apresentam questóes estruturais como gestão, financiamento, avaliação, valorizaçấo dos profissionais, entre outras? 
No próximo item, vamos buscar abordar, resumidamente, algumas dessas questóes nas proposiçóes sobre o SNE em debate e, em seguida, alguns pontos de tensão e disputa no Congresso Nacional.

\section{Institucionalização do Sistema Nacional de Educação: proposições em debate}

As formulações sobre o SNE ganharam novo fôlego nos governos Lula e Dilma, por meio de proposiçóes e políticas governamentais de grande incidência, bem como por açốes e proposiçôes do Congresso Nacional que contribuíram para o delineamento de políticas nacionais, articuladas ao esforço de maior cooperação federativa.

Tais movimentos e políticas sinalizaram para mais organicidade das políticas e gestão para a educação, envolvendo, entre outros, a ampliação da cobertura do financiamento público para a educação básica, por meio da aprovação da EC no 53/2006, da Lei no $11.494 / 2007$ e do Decreto no 6.253/2007, que tratam do FUNDEB, rompendo com a política focalizada no ensino fundamental vigente no FUNDEF; a aprovação da Lei no 11.738 , de 16 de julho de 2008, que trata do PSNP para os profissionais do magistério; a aprovação da EC no 59/2009, envolvendo as questôes já delineadas neste artigo, bem como a ampliação da educação básica obrigatória e sua universalização; a criação do Plano de Desenvolvimento da Educação (PDE) e do Plano de Açóes Articuladas (PAR) (Lei no 12.695, de 25 de julho de 2012) como instrumentos de planejamento; a aprovaçáo da Lei no 12.858, de 09 de setembro de 2013, destinando exclusivamente para a educação pública parcelas de recursos dos royalties, da participaçáo especial e do Fundo Social decorrentes da exploração de petróleo e gás natural; a criação do FNE, no ano de 2010.

O coroamento desse processo de proposição efetiva-se com a aprovação e a sanção, sem vetos, do PNE 2014/2024, que traz um conjunto de dispositivos, metas e estratégias para novos parâmetros na relação federativa e na efetivação das políticas educacionais, além de definir, no art. 13, a instituição, por meio de lei específica, no prazo de 2 anos, do SNE como responsável pela articulação entre os sistemas de ensino em regime de colaboração, para a efetivação das diretrizes e estratégias do PNE.

O grande desafio está na materialização do PNE, sobretudo a partir do cenário político Pós-Golpe Parlamentar de 2016, cujos desdobramentos sinalizam para a secundarização do PNE, seus comandos, dispositivos e prazos.

A institucionalização do SNE vem sendo objeto de proposições desde a aprovação da EC no 59/2009 e ganhou densidade com a aprovação do PNE e tem sido objeto de disputa, desde entáo. Abordaremos três dessas iniciativas, 
por serem estruturantes no debate atual: o Projeto de Lei Complementar (PLP) no 413/2014, em tramitação na Câmara dos Deputados; a proposição do FNE; a proposta do MEC; e, ao final, alguns pontos de disputa e tensão na tramitação da matéria. Importante situar, contudo, que a proposta do MEC aqui referida e tratada foi produzida pela Secretaria de Articulação com os Sistemas de Ensino (SASE) do MEC no governo anterior e foi secundarizada pelo governo atual. No entanto, a proposta se faz presente em vários momentos e dinâmicas, incluindo audiências públicas no Congresso Nacional. Nas disputas referentes à tramitação, pós 2016, ainda que o governo em exercício não tenha apresentado uma proposta de PLP, são consideradas as posiçóes explicitadas pelo MEC nos debates, sobretudo, no Parlamento.

Além das Conferências de Educação (CONAE e CONAPE), das discussōes em diferentes espaços institucionais de elaboração e debate, estes movimentos são canalizados para o Poder Legislativo, que vem gerando formulaçóes sobre o SNE no Congresso Nacional, notadamente na Câmara dos Deputados.

Em 2014, foi apresentado o Projeto de Lei Complementar (PLC) no 414 (PLP no 413/2014), de autoria do Deputado Ságuas Moraes (Partido dos Trabalhadores do Mato Grosso - PT-MT), que encabeça a tramitação de materiais relativos ao SNE. A proposição considera formulações do Grupo de Trabalho [19], instituído no âmbito da SASE do MEC. Com 31 artigos, no fundamental, espelha-se em formulaçóes apresentadas por Carlos Abicalil, entre os anos de 2010 e 2014.

A proposta, apresentada em julho de 2014, é formalizada logo após a aprovação do PNE, para atender ao comando do seu art. 13 (do corpo da lei), e da estratégia 20.9 do respectivo anexo. A proposta foi distribuída para apreciação pelas Comissôes de Educação, de Finanças e Tributação e de Constituiçẫo e Justiça e de Cidadania.

$\mathrm{Na}$ Comissão de Educação, foi designado relator em outubro de 2014, Deputado Glauber Braga (então no Partido Socialista Brasileiro do Rio de Janeiro - PSB-RJ). Um primeiro substitutivo é apresentado em dezembro de 2015.

São realizadas algumas audiências públicas para instruir a matéria e, em novembro de 2017, é apresentado novo PLP, de no 448/2018, de autoria do Deputado Giuseppe Vecci (Partido da Social Democracia Brasileira de Goiás PSDB-GO), que atende sugestáo do Fórum Nacional dos Conselhos Estaduais de Educação (FNCEE). O relator apresenta um novo substitutivo em dezembro de 2017.

Desde então, até meados de 2018, a proposição vem sendo pautada e retirada e movimentos de interlocução e construção de consensos entre autor, relator, Comissão de Educação (CE) e MEC (que não formaliza uma proposta) vêm se processando: em termos de forma, uma tensão entre uma proposta mais deta- 
lhada na regulamentação da cooperação e em relação às estruturas fundamentais do SNE; em termos de conteúdo, inúmeros pontos de dissenso, tais como o modelo de financiamento e participação da União, ancorado ou não em um conceito de custo aluno qualidade; o lugar institucional do PNE e o planejamento decenal articulado; as instâncias interfederativas; detalhamento de diretrizes e princípios que demarquem os grandes objetivos do SNE e uma concepção de educação que o sustente; estratégias e instrumentos de cooperação e regionalização para a educação (polos regionais, consórcios, arranjos), entre outros.

O FNE instituiu o grupo de trabalho (GT), com a finalidade de construir uma proposta de SNE cujo Documento Propositivo para o Debate Ampliado - PLC que institui o SNE e regulamenta a seção da educação na CF, especialmente os arts. 23 e 211 - foi aprovado pelo FNE. Importante destacar que essa proposta de PLP, construída pelo GT e aprovada pelo FNE, tem como base as deliberaçóes das conferências nacionais (CONEB, 2008; CONAE, 2010 e 2014). A discussão sobre a institucionalização do SNE se fez presente de maneira decisiva nessas conferências e a proposta do SNE foi a base para o eixo I do Documento-Referência da CONAPE, organizada pelo FNPE. Ou seja, o documento proposto pelo FNE guarda estreita coerência com as concepçóes deliberadas pelas conferências mencionadas.

A proposição do FNE com 47 artigos tem, por delimitação, instituir e regulamentar o SNE e fixar normas para a cooperação e a colaboração entre a União, os estados, o Distrito Federal (DF) e os municípios, com vistas à garantia do direito à educação, ao cumprimento das metas do PNE e ao disposto na LDB.

A proposta do FNE apresenta concepção abrangente sobre o SNE e, ao definir o PNE como eixo-base de normatização vinculante dos demais planos decenais de educação, sinaliza princípios, finalidades e objetivos; dispóe sobre as ações e os instrumentos de planejamento, incluindo a Instância Nacional Permanente de Negociação Federativa para a Educação Básica, instâncias permanentes de negociação em cada estado e o Fórum Ampliado dos Conselhos de Educação.

A proposta do FNE, ao abordar as instâncias normativas, define o CNE com funçóes normativas com composição federativa e com efetiva participação da sociedade civil; define o papel do FNE como órgão de proposição, mobilização, articulação e avaliação da política nacional de educação sem, contudo, detalhar a sua composição; define a gestão democrática como princípio a ser efetivado por meio de diretrizes nacionais a serem observadas como condição de acesso a recursos financeiros de caráter complementar da União.

A proposta do FNE define concepçáo ampla do Sistema Nacional de Avaliação articulando a educação básica e superior; estabelece referências sobre o financiamento da educação incluindo a definição de um padrão nacional de investimento para o financiamento anual da educação básica, bem como a com- 
plementaçáo compulsória da Uniấo para todos os estados. A discussão do Custo Aluno-Qualidade (CAQ) tem importante espaço nessa proposição, que ainda aborda a valorizaçáo dos profissionais da educação e define o Fórum Permanente de Valorização desses profissionais com composição paritária, entre outros.

A proposição do Anteprojeto de Lei Complementar, construído pelo MEC $^{3}$ e finalizado em 2016, resulta de um processo de trabalho sob o comando da SASE/MEC, antes do impeachment da presidenta. A partir de sucessivos debates, propõe a regulamentação do parágrafo único do art. $23 \mathrm{da} \mathrm{CF}$, a instituição do SNE, e fixa normas de cooperaçáo federativa entre a União, os estados, o DF e os municípios, definindo responsabilidades educacionais para garantir a educação como direito social e para cumprir o disposto no PNE e na LDB. A referida proposta guarda relação com a proposta do FNE, a despeito de algumas diferenças e proposiçóes, com destaque para o financiamento, o CAQ e o papel da União.

A proposta do MEC apresenta concepção sobre o SNE como sistema, ressalta sua atuação de forma colaborativa, articulada e coordenada; estabelece objetivos gerais e específicos da cooperação federativa e da colaboração em matéria educacional; prevê a organização, pelos entes federativos, de seus sistemas de ensino; define o PNE como eixo-base de normatização vinculante dos demais planos decenais de educação; dispóe sobre as açóes e os instrumentos de planejamento, incluindo Instâncias Permanentes de Negociação Federativa para a Educação Básica (Comissão Tripartite de Gestão Administrativa e Financeira e Comissão Tripartite de Gestão Normativa).

A proposta do MEC, a abordar as instâncias normativas, define o CNE com funções normativas, deliberativas e de assessoramento ao Ministro da Educação e não delimita a composição deste órgão; define o papel do FNE como órgão de mobilização e articulação da sociedade civil, sem, contudo, detalhar a sua composição; define a gestão democrática, sem avançar na sua definição, como uma das dimensōes a serem consideradas enquanto referencial de qualidade.

A proposta do MEC traz um capítulo específico sobre o Sistema Nacional de Avaliação, articulando processos e mecanismos de avaliação da educação básica e superior; de igual modo, estabelece parâmetros sobre o financiamento da educação, incluindo uma referência nacional de investimento, adequado ao orçamento público, para o financiamento da educação básica, bem como define a complementação compulsória da Uniáo para todos os estados. Essa proposta aborda a valorizaçáo dos profissionais da educação e define o Fórum Permanente de Valorização dos Profissionais, estabelece que os estados, o DF e os municípios devem elaborar ou adequar o Plano de Carreira e Remuneração do Magistério de acordo com as diretrizes a serem pactuadas na Comissão Tripartite e aprovadas pelo CNE.

São três proposiçóes que guardam convergência em muitas questôes, mas que apresentam disputas em várias outras. Merecem realce novas discussóes 
encaminhadas pelo MEC, após o impeachment, em conexáo com as políticas adotadas pelo Ministério, na esteira das políticas de ajustes e mudanças nas políticas e gestão da educação nacional. Destacamos algumas diferenciaçôes importantes, considerando que o MEC não formalizou uma proposta, restando apenas as sinalizaçôes que produzem debates públicos e reuniōes de trabalho.

O principal tema polêmico e não consensuado na discussão acerca do SNE, no estágio do primeiro semestre do ano de 2018, é o financiamento da educação, ao qual se articula o papel complementar e suplementar da Uniáo e o reforço ao conceito de um CAQ de referência. Tanto a proposiçáo original (PLP no 413) como as proposiçóes vinculadas demarcam que a transferência de recursos da União deve colaborar para garantir padrão mínimo de oportunidades educacionais e visar à promoção da equidade e da qualidade em âmbito nacional, mencionando ou não CAQ e/ou Custo Aluno-Qualidade Inicial (CAQi). O MEC resiste à proposição, já que a complementação necessária para viabilizar esse parâmetro para o financiamento da educação (tratado nas estratégias 20.6, 20.7, 20.8 e 20.10 do PNE) seria fundamentalmente de sua responsabilidade. Trata-se de questão estrutural a ser equacionada, requerendo a definição CAQi e CAQ como fundamento basilar para a garantia da democratização do acesso e da melhoria da educação básica, postura esta ratificada pela CONAPE, 2018.

Merece atenção o lugar institucional e a estatura ocupada pelo PNE na articulação do SNE, dentro da proposta de regulamentação da cooperação federativa e da instituição do SNE. Aprovada uma proposição, convém atentar se ela se confirmará como plano de caráter vinculante, instrumento de gestáo e de mobilização da sociedade a orientar o planejamento decenal correspondente, espraiado nos consentâneos planos municipais, estaduais e distrital de educação ao longo dos territórios, que devem ser aprovados com ampla participação da sociedade. Ou seja, a síntese poderá demarcar ou não o cumprimento das metas do PNE e demais planos decenais de educação, no âmbito dos estados, do DF e dos municípios, como referência fundamental a orientar a cooperação federativa.

A proposta mais "minimalista" que o MEC atual sinaliza tende a reduzir o exercício da pactuação federativa para o cumprimento do PNE e dos demais planos à prestação de assistência técnica para elaboração e revisão dos planos.

A atuação propositiva do MEC e do Governo Federal, por meio das políticas de ajustes em curso, com centralidade para $\mathrm{EC} \mathrm{n}^{\circ} 95$, de 15 de dezembro de 2016, que altera o Ato das Disposiçóes Constitucionais Transitórias, para instituir o novo regime fiscal, impóe limites efetivos às políticas educacionais e poderá inviabilizar o PNE no cumprimento de seus comandos, metas, estratégias e prazos. Essas políticas impactam, sobremaneira, a relação e a pactuação federativa e, por certo, a institucionalização do SNE. 
Em relação às instâncias federativas, as proposiçóes formalizadas, PLP original, substitutivos e apenso, preservam a orientação de criação de instâncias permanentes de negociação e cooperação entre a União, os estados, o DF e os municípios, seja nacional, seja no âmbito de cada estado. Diferenciam-se na nomenclatura adotada, na delimitação de suas atribuiçôes, no detalhamento ou não de sua composição (com ou sem participação social e restrita aos gestores) e no caráter vinculante de suas decisóes, via normas operacionais vinculantes ou não. Aqui, outro obstáculo ressaltado pelo governo é ressalvar que decisōes das quais resultarem obrigaçóes administrativas ou financeiras exigem aprovação qualificada, o que não se coaduna à própria natureza de uma instância que deve ser de negociação e pactuação.

As propostas formalizadas detalham diretrizes, objetivos e princípios afirmativos em relação aos propósitos do $\mathrm{SNE}$, da cooperação federativa e de uma concepção ampla e humanista de educação, ao mesmo tempo em que incorporam inovações em relação à legislação atual, em uma Lei Complementar (mais estável), como a solidariedade federativa e a participação da sociedade civil, entre outros aspectos. O MEC sugere uma proposta que "não repita" diretrizes e objetivos supostamente já consagrados na legislação educacional em vigor. São perspectivas distintas, que carecem de melhor aprofundamento, sobretudo sobre os desdobramentos daí decorrentes.

Em relação aos instrumentos e mecanismos "mais concretos" a materializar a cooperação, as propostas se diferenciam: ao afirmar ou não que as disposiçóes do PNE constituem normatização vinculante dos planos estaduais, distrital e municipais de educação a ele consequentes; ao demarcar ou não que a regulamentação da cooperação entre estados e municípios deve se dar pela via de leis sucedâneas - para garantir a sustentabilidade e a estabilidade dos pactos; ao especificar ou náo polos regionais, consórcios ou arranjos de desenvolvimento da educação ${ }^{4}$. Em relação a estes, a diferenciação não é só de nomenclatura, mas diz respeito à liderança do exercício do pacto (se de dirigentes e órgãos públicos ou de assessorias e consultorias privadas ou do "terceiro setor") e, ainda, ao caráter mais transitório, frágil e instável da pactuação, notadamente se comparados consórcios públicos (que requerem aprovação pelas casas legislativas, o que confere maior legitimidade e estabilidade) e arranjos não constituídos enquanto figuras jurídicas e com limites em relação à participação e ao acompanhamento social, e se constituem, em geral, como acordos informais. Ademais, há a questão do acesso ao fundo público por meio de tais configuraçóes. Se considerarmos o avanço do setor privado sobre o fundo público a partir de várias perspectivas em curso, essa questão assume grande complexidade, requerendo melhor delineamento das figuras jurídicas, como destacado.

Outra diferenciação importante, entre as proposições em debate mais atual, diz respeito à exclusão de recursos destinados ao pagamento dos profissio- 
nais do magistério da educação básica em efetivo exercício dos limites dispostos na Lei Complementar no 101/2000 para despesas com pessoal, assim como aquelas derivadas da expansão da oferta educacional pública. Proposta original e substitutivo tocam nesse tema, enquanto o Governo Federal, na Emenda Constitucional do Teto dos Gastos, recusa-o, por coerência programática.

São questôes estratégicas cujas disputas de concepções e proposições delineiam o complexo cenário de discussão e disputa sobre a institucionalização do SNE.

\section{Considerações finais}

Ao longo do texto situamos historicamente a trajetória das discussões e proposiçôes sobre o SNE; em seguida, inventariamos algumas concepçóes e questóes estruturantes sobre os limites e as potencialidades do SNE; e na última seção, apresentamos três proposiçóes de PLC em debate, situando, ainda, o processo de tramitação na Câmara dos Deputados e o levantamento de questóes em disputa. A participaçáo do MEC, no último período, efetivou-se sem a apresentação de uma proposta executiva, restringindo-se ao substrato das políticas e reformas engendradas pelo Governo Federal e por meio de debates e sinalização de posiçóes do MEC face à matéria, sobretudo, no Legislativo Federal.

A tramitação da matéria, no Congresso Nacional, faz-se presente com avanços e recuos. Importante náo perder de vista que o cenário atual é mais complexo, fortemente marcado por uma agenda de retrocessos no campo social e pela centralidade de políticas de governo, em detrimento às políticas de Estado para a educação nacional.

As principais questôes em disputa e que merecem atenção pormenorizada no processo de disputa pela institucionalização do SNE envolvem a centralidade ou não do PNE como epicentro das políticas de Estado para a educação; as condiçóes objetivas para a institucionalização do SNE, incluindo o financiamento da educação, a definição do CAQi e CAQ e a garantia do papel complementar e suplementar da União; o delineamento e o equilíbrio em torno das atribuiçōes, composiçāo e objetivos das instâncias federativas, bem como do caráter vinculante de suas decisóes; o papel e a autonomia dos órgáos normativos e dos fóruns de educaçáo e os instrumentos e mecanismos de cooperação, que serão demarcados e induzidos; a concepção de avaliação; a garantia da valorização dos profissionais da educação, entre outros.

Essas e outras questôes estão no cerne das concepçóes em disputa no cenário atual e, de certo modo, retratam a postura política atual do MEC na secundarização do PNE e, por conseguinte, da discussão sobre a institucionalização do SNE. A materialização do Golpe Parlamentar, que resultou no afastamento da presidenta eleita, vai-se efetivando por meio de um reordenamento conservador das políticas e da gestão para a educação nacional. Essa lógica política se efetiva pela retomada das 
políticas de governo, em detrimento de movimentos e processos que se organizavam em torno de políticas de Estado. A prova inconteste desse movimento tem sido a secundarização do PNE, seus comandos e prazos, por meio das políticas em curso, sobretudo as de ajuste fiscal restritivo, expresso de maneira estrutural por meio da aprovação da Proposta de Emenda Constitucional (PEC) no 95 , que congelou os investimentos na área social por 20 anos, o que, na prática, inviabiliza a materialização do PNE, suas metas e estratégias e, por outro lado, naturaliza e consolida os processos de mercantilização e financeirização da educação no país.

Esse novo cenário marcado por políticas de ajustes cuja lógica se contrapóe ao avanço das políticas sociais, entre elas a garantia do direito à educação, é marcado por retrocessos também na agenda de maior articulaçáo federativa por meio de normas de cooperação e arenas federativas efetivadas por processos de descentralização qualificada, instâncias interfederativas de caráter vinculante, entre outros. As atuais políticas caminham na contramão de um sistema nacional de educação por meio da retomada de políticas marcadas pela centralização da União, em detrimento da consolidação de normas de cooperação e colaboraçấo entre os entes federados.

Isso requer proposiçóes efetivas visando à institucionalizaçáo do $\mathrm{SNE}$, em atendimento explícito ao comando do PNE, sobretudo se considerarmos a enorme dívida histórica do Estado brasileiro com a garantia do direito à educação para todos, em uma República Federativa marcada por desigualdades e assimetrias de toda ordem.

A discussão sobre o SNE é relevante e necessária, na medida em que desvela concepçóes distintas na organizaçáo e na gestão da educação, secundadas por processos complexos de interpenetração entre as esferas pública e privada na disputa pelo fundo público, num cenário de minimização do papel do Estado face às políticas públicas. Nesse processo, é fundamental o fortalecimento do FNPE e a defesa intransigente das deliberaçóes da CONAPE 2018 e da Carta de Belo Horizonte, que reafirmam a centralidade do PNE como epicentro das políticas de Estado para a educação e, nesse contexto, a institucionalização de um SNE democrático.

\section{Notas}

1. A respeito do PNE 2001-2010, Dourado (2010, p. 682-683) afirma: "O PNE teve tramitação sui generis, envolvendo o embate entre dois projetos: o PNE da sociedade brasileira e a proposta de PNE encaminhada pelo Executivo Federal”. Os dois expressavam concepções e prioridades educacionais distintas, sobretudo na abrangência das políticas, em seu financiamento e gestão, bem como no diagnóstico, prioridades, diretrizes e metas. A proposta de PNE da sociedade brasileira previa um conjunto de princípios que náo foram incorporados no plano aprovado, destacando-se a instituição do Sistema Nacional de Educação e do Fórum Nacional de Educação, a redefinição do Conselho Nacional de Educação e a garantia de ampliação do investimento em educação pública de $10 \%$ do PIB. "A aprovação do PNE foi resultado, portanto, da hegemonia governamental no Congresso Nacional, que buscou traduzir a lógica de suas políticas em curso". 
2. O FNPE foi criado por um grupo de entidades, após alteração unilateral da composição do FNE pelo MEC. Esse fórum organizou a Conferência Nacional Popular de Educação, que ocorreu em Belo Horizonte, Minas Gerais, entre os dias 24 e 26 de maio de 2018. A CONAPE foi precedida de conferências, municipais, estaduais e distrital, e contou com expressiva participação social.

3. A proposta do MEC resulta de GT sobre o comando da SASE/MEC, sob responsabilidade de Binho Marques, em que se destacam o texto Instituir um Sistema Nacional de Educação: agenda obrigatória para o país e o Anteprojeto de Lei Complementar (com 51 artigos), que considera a formulaçáo do FNE. Sobre o SNE e o PNE destaco, entre outros, alguns artigos que subsidiaram os debates em diferentes arenas: Abicalil (2002, 2011, 2012, 2013 e 2014); Almeida Junior, Bordignon, Gadotti e Cunha (2014); Araújo (2010); Brasil (2014a, 2015); Cunha, Gadotti, Bordignon e Nogueira (2014); Cury (2002 e 2008); Dourado (2007, 2011 e 2013); e Saviani (2010a, 2010b).

4. Sobre arranjos de cooperação e fundo público, ver Abicalil (2013).

\section{Referências}

ABICALIL, C.A. Construindo o Sistema Nacional Articulado de Educação. In: CONFERÊNCIA NACIONAL DE EDUCAÇÃO, 2010, Brasília. Anais... Brasília: MEC, 2011. p. 100-113.

- Federalismo Brasileiro e Cooperação interfederativa em educação: entre as autonomias e a equidade. Roteiro, v. 39, n. 1, p. 11-38, 2014. Disponível em: <http:// editora.unoesc.edu.br/index.php/roteiro/article/view/4620>. Acesso em: 10 jan. 2018.

. O federalismo e o Sistema Nacional de Educação: uma oportunidade fecunda. Retratos da Escola, Brasília, v. 6, n. 10, p. 21-37, jan./jun. 2012. http://dx.doi.org/10.22420/ $\underline{\text { rde.v6i10.168 }}$

Sistema Nacional de Educação Básica: o nó da Avaliação. Educação e Sociedade, Campinas, v. 23, n. 80, p. 253-274, set. 2002.

Sistema Nacional de Educação: os arranjos na cooperação, parceria e cobiça sobre o fundo público na educação básica. Educação \& Sociedade, v. 34, n. 124, p. 803-828, set. 2013. http://dx.doi.org/10.1590/S0101-73302013000300009

ALMEIDA JUNIOR, A.M.; BORDIGNON, G.; GADOTTI, M.; CUNHA, C. Sistema nacional de educação: uma agenda necessária. In: CUNHA, C.; GADOTTI, M.; BORDIGNON, G.; NOGUEIRA, F. (Orgs.). O sistema nacional de educação: diversos olhares 80 anos após o Manifesto. Brasília: Ministério da Educação, 2014.

ARAÚJO, G.C. Constituição, federação e propostas para o novo Plano Nacional de Educação: análise das propostas de organização nacional da educação brasileira a partir do regime de colaboração. Educação \& Sociedade, v. 31, n. 112, p. 749-768, set. 2010. http:// dx.doi.org/10.1590/S0101-73302010000300006

AZEVEDO, J.M.I. Implicações da nova lógica de ação do Estado para a educação municipal. Educaçâo \& Sociedade, v. 23, n. 80, p. 49-71, 2002. http://dx.doi.org/10.1590/ $\underline{\text { S0101-73302002008000004 }}$ 
BRASIL. Manifesto dos Pioneiros da Educação Nova (1932) e dos educadores 1959. Recife: Fundação Joaquim Nabuco, Massangana, 2010. 122 p. (Coleção Educadores.)

- Ministério da Educação. Conferência Nacional de Educação Básica: Relatório Final. Brasília: Ministério da Educação, 2008. Disponível em: <http://portal.mec.gov.br/ arquivos/conferencia/documentos/doc_final.pdf>. Acesso em: 20 jan. 2018.

- Ministério da Educação. Secretaria de Articulação com os Sistemas de Ensino. Instituir um Sistema Nacional de Educaçâo: agenda obrigatória para o país. 2015. Disponível em: <http://pne.mec.gov.br/images/pdf/SNE junho 2015.pdf>. Acesso em: 2 jul. 2017.

. Ministério da Educação. Secretaria de Articulação com os Sistemas de Ensino. O Sistema Nacional de Educação: diversos olhares 80 anos após o Manifesto. Brasília: Ministério da Educação/Secretaria de Articulação com os Sistemas de Ensino, 2014a. Disponível em: <http://pne.mec.gov.br/images/pdf/livro pioneiros final.pdf $>$. Acesso em: 20 jan. 2018.

. Presidência da República. Casa Civil. Subchefia para Assuntos Jurídicos. Lei $n^{o}$ 13.005, de 25 de junho de 2014. Aprova o Plano Nacional de Educação - PNE e dá outras providências. 2014b. Disponível em: <http://www.planalto.gov.br/ccivil_03/_ato20112014/2014/lei/l13005.htm>. Acesso em: 10 jan. 2018.

Projeto de lei $n^{\circ}$ 1.258, de 1988. Fixa as diretrizes e bases da Educação Nacional. 1988. Disponível em: <http://www.camara.gov.br/proposicoesWeb/ fichadetramitacao?idProposicao=189757>. Acesso em: 20 maio 2018.

CURY, C.R.J. A Educação Básica no Brasil. Educação \& Sociedade, v. 23, n. 80, p. 168-200, 2002.

Sistema nacional de educação: desafio para uma educação igualitária e federativa. Educação \& Sociedade, v. 29, n. 105, p. 1187-1209, dez. 2008. http://dx.doi. org/10.1590/S0101-73302008000400012

DOURADO, L.F. Avaliação do Plano Nacional de Educação 2001-2009: questóes estruturais e conjunturais de uma política. Educação \& Sociedade, Campinas, v. 31 , n. 112 , p. 677-705, jul.-set. 2010. http://dx.doi.org/10.1590/S0101$\underline{73302010000300003}$

Plano Nacional de Educação: o epicentro das políticas de estado para a educação brasileira. Goiânia: Editora da Imprensa Universitária/ANPAE, 2017. 216 p.

Políticas e gestão da educação básica no Brasil: limites e perspectivas. Educação e Sociedade, Campinas, v. 28, n. 100, p. 921-946, out. 2007. http://dx.doi.org/10.1590/ $\underline{\text { S0101-73302007000300014 }}$

. Sistema Nacional de Educação, Federalismo e os obstáculos ao direito à educação básica. Educação \& Sociedade, v. 34, n. 124, p. 761-785, set. 2013. http://dx.doi. org/10.1590/S0101-73302013000300007

(Org.). Plano Nacional de Educação (2011-2020): avaliação e perspectivas. 2. ed. Goiânia: Editora da UFG; Belo Horizonte: Autêntica, 2011. 
DUARTE, M.R.T.; SANTOS, M.R.S. Sistema Nacional de Educação e relaçóes intergovernamentais no Brasil. Educação e Sociedade, v. 35, n. 129, p. 1115-1136, dez. 2014. http://dx.doi.org/10.1590/ES0101-73302014143803

HORTA, J.S.B. Plano Nacional de Educação da Tecnocracia à Participação Democrática. In: CURY, C.R.J.; HORTA, J.S.B.; BRITO, V.L. Medo à liberdade e compromisso democrático: LDB e Plano Nacional de Educação. São Paulo: Editora do Brasil S/A, 1997. p. 137-206.

MENDES, D.T. O Planejamento Educacional no Brasil. Rio de Janeiro: EdUERJ, 2000.

SAVIANI, D. Organização da educação nacional: sistema e conselho nacional de educação, plano e fórum nacional de educação. Educação e Sociedade, v. 31, n. 112, p. 769-787, set. 2010a.

. Sistema Nacional de Educação articulado ao Plano Nacional de Educação. Revista Brasileira de Educação, v. 15, n. 44, maio/ago. 2010b. Disponível em: <http://www.scielo. br/pdf/rbedu/v15n44/v15n44a13.pdf>. Acesso em: 20 maio 2018.

Recebido em 10 de junho de 2018.

Aceito em 11 de junho de 2018. 